\title{
LA ORGANIZACIÓN NORMATIVA DE LA COMISIÓN CENTRAL DE SEÑORAS COOPERADORAS SALESIANAS: GÉNERO Y SOCIABILIDAD. ARGENTINA, 1900-1926
}

\author{
The normative organization of the Central \\ Commission of Salesian Women Cooperators: gender \\ and sociability. Argentina, 1900-1926
}

\section{Lucía Bracamonte*}

\begin{abstract}
RESUMEN
El objetivo de este artículo es analizar la organización normativa de la Comisión Central de Señoras Cooperadoras Salesianas entre 1900 y 1926 desde un punto de vista de género, a fin de observar los conflictos y los consensos que construyeron sacerdotes y cooperadoras en torno a su formulación y puesta en práctica. Se estudiarán diversos documentos reglamentarios relativos a la mencionada comisión, localizados en el Archivo Central Salesiano de Buenos Aires y en el Archivo Histórico Salesiano Patagónico de Bahía Blanca. Las cooperadoras actuaban colectivamente bajo la tutela sacerdotal que intentaba canalizar las iniciativas individuales e impedir las transgresiones reglamentando por escrito su accionar. Sin embargo, tuvieron la posibilidad, a través de las Presidentas de la Comisión, de hacer conocer a los sacerdotes sus opiniones sobre la normativa y de influir en su diseño.
\end{abstract}

Palabras clave: salesianos; comisiones; reglamentación

* Doctora en Historia. Investigadora del Consejo Nacional de Investigaciones Científicas y Técnicas (CONICET), Centro de Estudios Regionales "Prof. Félix Weinberg", Departamento de Humanidades, Universidad Nacional del Sur, Bahía Blanca, Argentina. La investigación fue financiada por el CONICET a través del proyecto: "Cultura política y sociabilidad en Bahía Blanca durante el siglo XX”, dirigido por la Dra. Mabel N. Cernadas. E-mail: luciab@criba.edu.ar 


\begin{abstract}
The objective of this work is to analyze the normative organization of the Central Commission of Salesian Women Cooperators between 1900 and 1926 from a gender viewpoint to observe the conflicts and consensus built by priests and cooperators around its definition and start up. Several normative documents related to the commission and located in the Central Salesian Archive in Buenos Aires and the Historic Patagonic Salesian Archive in Bahia Blanca are studied. Women cooperators worked in collaboration under the supervision of the priests that tried to channel the individual initiatives and avoid the transgressions ruling with documents their actions. However, the women cooperators were able to make their opinion known to the priests and to influence in the final design of the rules.
\end{abstract}

Key-words: salesian; commisions; rules

\title{
Introducción
}

Entre fines del siglo XIX y principios del siglo XX, los sacerdotes salesianos fundaron en la Argentina oratorios festivos, colegios y asilos dirigidos a formar buenos cristianos y honrados ciudadanos. Además de ello, realizaron labores pastorales, acompañaron a las familias inmigrantes italianas, misionaron en la zona patagónica, fundaron círculos de obreros y pusieron en circulación distintas publicaciones. El proyecto que desplegaron se articuló parcialmente, aunque no sin tensiones, con las intenciones de civilizar, moralizar y controlar a los sectores populares ostentadas por los núcleos dirigentes de impronta liberal. Aunaba a estos actores la preocupación por la denominada "cuestión social" 1, especialmente por la situación de los niños y jóvenes considerados en riesgo debido a su pobreza, abandono, vagancia y analfabetismo. A sus ojos, esos

1 La "cuestión social" era el conjunto de problemáticas sociales que emergieron como consecuencia de la industrialización, la urbanización y la inmigración, entre las que se encontraban los conflictos obreros, el pauperismo, la marginalidad, la delincuencia, la prostitución, el hacinamiento y las enfermedades. 
menores podían alterar el orden, convertirse en criminales y recibir influencias perniciosas como las del socialismo y el anarquismo.

Desde el arribo de los primeros clérigos de la congregación en 1875, se registró en diversos lugares la participación de mujeres en favor de la Obra de Don Bosco. Las cooperadoras salesianas formaban parte de la Pía Unión de Cooperadores Salesianos, entidad subordinada al Rector Mayor de la Sociedad de San Francisco de Sales $^{2}$. Esta presencia femenina fue advertida por quienes se dedicaron a reconstruir la historia de los salesianos en la Argentina. ${ }^{3}$ Sin embargo, aún no se han estudiado en profundidad algunos aspectos, como la emergencia y el desenvolvimiento de los grupos formalizados de benefactoras de la Capital Federal, ni se ha abordado el tema desde la línea de la historia de mujeres. Dentro de este último campo, los estudios sobre la asistencia social y el protagonismo colectivo de las mujeres en relación a la misma se intensificaron en los últimos años. Varios de ellos tuvieron en cuenta a las asociaciones confesionales y laicas integradas por católicas en la etapa de modernización, ya fuera entendiéndolas como expresiones de un maternalismo "sentimental" o "conservador" o como manifestaciones de un "feminismo católico". El presente trabajo se enmarca en el

2 La Sociedad de San Francisco de Sales fue fundada en Turín en 1859 por Juan Melchor Bosco. Luego de su muerte, la conducción de la congregación quedó en manos del Rector Mayor. Existían también Inspectores radicados en las diferentes zonas hacia las cuales se había expandido la Obra.

3 Gran parte de la producción se ha concentrado en la labor salesiana en la región patagónica. Véase el siguiente libro de publicación reciente: FRESIA, Ariel, PICCA, Juan V. y NICOLETTI, María Andrea (comps.). Estado e Iglesia en Patagonia: Repensando las misiones salesianas (1880-1916). Rosario: Prohistoria Ediciones, 2016. Con respecto a otros lugares: FRESIA, Ariel. Religión, educación y vida cotidiana en Rodeo del Medio, siglo XX: Contribución a una historia social de los Salesianos de Don Bosco en la campaña mendocina. Buenos Aires: Dunken, 2005; LANDABURU, Alejandra. Niñez, juventud y educación: El proyecto salesiano en Tucumán. 1916-1931. Tucumán: Edunt, 2012; MORETTI, Nicolás D. Buenos cristianos y honrados ciudadanos: La obra salesiana y la cuestión social. Córdoba, 1905-1930. Córdoba: CEH, 2014. El único trabajo de las últimas décadas que reconstruye algunos aspectos sobre esta comisión es una ponencia referida al Territorio Nacional de Santa Cruz: PIERINI, María de los Milagros. Con la ayuda de Dios... y de los hombres: la obra de los Cooperadores Salesianos en el Territorio Nacional de Santa Cruz. En: X Jornadas Interescuelas/Departamentos de Historia. Rosario: Universidad Nacional del Litoral, 2005. Disponible en: http://cdsa.aacademica.org/000-006/313.pdf

4 ERASO, Yolanda. Maternalismo, religión y asistencia: La Sociedad de Señoras de San Vicente de Paul en Córdoba, Argentina. En: ERASO, Yolanda (comp.) Mujeres y Asistencia Social en Latinoamérica, siglos XIX y XX: Argentina, Colombia, México, Perú y Uruguay. Córdoba: Alción, 2009, pp. 199-239; VIDAL, Gardenia. El Feminismo Católico de 
propósito general de ese conjunto de producciones tendiente a rastrear la presencia activa de las militantes en la acción social católica. En este sentido, buscamos abonar la mirada del catolicismo como heterogéneo y plural y enfocar a quienes no pertenecieron a la cúpula eclesiástica, al orden sacerdotal ni al conjunto de fieles que se limitaban a la práctica ordinaria y privada de la religión.

En este contexto, nos situamos en la problemática amplia del grado de univocidad y eficiencia de los dispositivos normalizadores del catolicismo, los cuales estaban dirigidos a modelar subjetividades y prácticas sociales a partir de las concepciones sobre la femineidad y la masculinidad construidas y difundidas por la Iglesia. Las experiencias colectivas en el campo de la asistencia conformaron formas de acción pública de las mujeres, legitimadas por sus fines benéficos, que matizaron la concepción predominante de lo femenino centrada en la primacía del ámbito doméstico. El objetivo específico del presente artículo es analizar la organización normativa de la Comisión Central de Señoras Cooperadoras Salesianas a principios del siglo XX desde un punto de vista de género, a fin de observar los conflictos y los consensos que construyeron sacerdotes y cooperadoras en torno a su formulación y puesta en práctica. El lapso seleccionado se extiende desde 1900, año en que se constituyeron las primeras comisiones centrales de cooperadores/as salesianos/as, hasta 1926, fecha en que la regulación y el campo de acción de la comisión que nucleaba a las mujeres sufrieron importantes cambios.

\footnotetext{
Córdoba: Congregación de Ntra. Sra. de Lourdes y San José, 1944-1955. Delaware Review of Latin American Studies, vol. 17, núm. 2, 2016. Disponible en: http://udspace.udel.edu/handle/19716/19837. Otras investigaciones recientes en este campo son las siguientes: GUY, Donna J. Las mujeres y la construcción del Estado de Bienestar: Caridad y creación de derechos en Argentina. Buenos Aires: Prometeo libros, 2011; VACA, Rosana. Las reglas de la caridad: Las Damas de Caridad de San Vicente de Paúl, Buenos Aires (18661910). Rosario: Prohistoria Ediciones, 2013; DALLA-CORTE CABALLERO, Gabriela. El Archivo de Señales del Hogar del Huérfano de Rosario: Niñez, identidad y migración (1879. 1914), e-book, Rosario: Prohistoria Ediciones, 2013; DALLA-CORTE CABALLERO, Gabriela, ULLOQUE, Marcelo y VACA, Rosana. La mano que da. 160 años de la Sociedad de beneficencia de Rosario. Rosario: Prohistoria Ediciones, 2014; GONÇALVES ALVES y otros (coords.) Dossier Historia de la asistencia en Brasil y Argentina: saberes, experiencias y prácticas. Delaware Review of Latin American Studies, vol. 17, num. 2, 2016. Disponible en: http://udspace.udel.edu/handle/19716/19840
} 
El corpus de la investigación está compuesto por diversas fuentes relativas a la Comisión Central, localizadas en el Archivo Central Salesiano de Buenos Aires y en el Archivo Histórico Salesiano Patagónico de Bahía Blanca. Examinaremos en particular el Programa de la Comisión Auxiliar de Señoras Cooperadoras y el Reglamento General de la Comisión Central de Señoras Cooperadoras Salesianas de Buenos Aires, por tratarse de normativas emitidas en la Argentina. También tomaremos en cuenta diversos textos que delineaban el marco general de actuación de los/as cooperadores/as a nivel mundial. Además de este tipo de documentos que refleja la postura oficial de los sacerdotes sobre la naturaleza de los agrupamientos femeninos, analizaremos las cartas de las Presidentas de la Comisión que hacen referencia a cuestiones normativas. Estas últimas remiten a la experiencia de mujeres situadas en roles dirigentes y permiten acceder, aunque de manera parcial, a las preocupaciones, conflictos y deseos de sus productoras. En conjunto, estos materiales permiten realizar un análisis de carácter morfológico y funcional y, además, ofrecen la posibilidad de adentrarse en las relaciones y representaciones de género.

A los fines de esta indagación, consideramos al género como conjunto de funciones sociales sexuadas y representaciones referidas a la masculinidad y la femineidad. Esta última categoría es entendida como una construcción sociocultural que prescribe cómo deben ser, sentir, pensar y comportarse las mujeres. Es un concepto definido de manera relacional, en oposición al de masculinidad, y varía de acuerdo a la época, el lugar, el estrato social, la etnia, la generación y la etapa del ciclo de vida en que se encuentren las personas. Se internaliza a través de la socialización de género, que asigna valores, normas, costumbres, estereotipos y roles, teniendo lugar de manera primaria en la familia y de manera secundaria en los demás escenarios de interacción que transitan los sujetos durante sus vidas, en los cuales actúan otros agentes socializadores como la escuela, los medios de comunicación y la Iglesia. ${ }^{5}$ De manera subsidiaria,

5 COBO BEDIA, Rosa. Género. En: AMORÓS, Celia. (dir.). Diez palabras clave sobre mujer. Navarra: Verbo Divino, 1995, pp. 55-83; COBO BEDIA, Rosa. El género en las ciencias sociales. Cuadernos de Trabajo Social, vol. 18, 2005, pp. 249-258; COBO BEDIA, Rosa. Otro recorrido por las ciencias sociales: género y teoría crítica. En: APARICIO GARCÍA, Marta y otras 
emplearemos la noción de sociabilidad, definida por Pilar González Bernaldo de Quirós como una herramienta que "remite a prácticas sociales que ponen en relación un grupo de individuos que efectivamente participan de ellas y apunta a analizar el papel que pueden jugar esos vínculos". ${ }^{6}$ En este caso, focalizaremos un ámbito de tipo asociativo, es decir, un territorio de sociabilidad mayormente formal expresada en normas. En tal sentido, consideramos que la sociabilidad supone la existencia de reglas y valores compartidos, y que si bien la norma no determina la conducta, ya que los individuos pueden transgredirla, reformularla y rechazarla, no deja de ser un elemento que incide en la toma de decisiones.

En este contexto, identificaremos en los documentos las definiciones sexuales, que se ocupan de señalar naturalezas o esencias específicas para cada sexo y de proyectar esa distinción a la sociedad en forma de ámbitos divididos dualmente y jerarquizados con predominio masculino. Al mismo tiempo, procuraremos observar cómo influyeron las nociones sobre la femineidad en el diseño normativo de prácticas de sociabilidad asociativa. Paralelamente, examinaremos la incidencia que tuvieron los lazos generados entre las cooperadoras y los sacerdotes en la toma de decisiones acerca de la regulación del accionar de la Comisión.

Como punto de partida, planteamos que las normativas estudiadas, enraizadas en las concepciones de femineidad de la Iglesia y destinadas a encauzar la acción social colectiva de estas "damas" y "señoritas" de la elite de Buenos Aires, acompañaron y posibilitaron prácticas novedosas de sociabilidad e intervención pública. A través de ellas, del mismo modo que otras benefactoras de su época, no solamente podían obtener fondos y proveer asistencia material sino también erigirse en agentes de control e integración de niños de los sectores populares y en sujetos incluidos políticamente. A modo de hipótesis, sostenemos que las cooperadoras actuaban colectivamente bajo la tutela sacerdotal que intentaba canalizar las iniciativas

(eds.). Cuadernos de género: Políticas y acciones de género. Madrid: Universidad Complutense, 2009.

6 GONZÁLEZ BERNALDO DE QUIRÓS, Pilar. La "sociabilidad” y la historia política. Nuevo Mundo. Mundos Nuevos, 17 de febrero de 2008. Disponible en: https://nuevomundo.revues.org/24082 
individuales e impedir las transgresiones reglamentando por escrito su accionar. Sin embargo, tuvieron la posibilidad, a través de las Presidentas de la Comisión, de hacer conocer a los sacerdotes sus opiniones sobre la normativa y de influir en su diseño.

\section{Surgimiento y organización normativa de la Comisión Central}

Entre 1880 y 1930 la Argentina atravesó un proceso de modernización en materia económica debido a su inserción en el modelo agroexportador, que conllevó el crecimiento de las ciudades y regiones directamente involucradas en el mismo como productoras de materias primas y/o nodos ferroportuarios. Además, se produjo una complejización de la estructura social por la conformación de una elite nacional y de las clases medias y obreras ligadas a la inmigración masiva. Sin embargo, el progreso no tuvo correlato en otras áreas menos materiales y más subjetivas de la vida social, por lo cual no puede hablarse propiamente de modernidad. Como señala Dora Barrancos, aunque avanzaron los propósitos civilistas y laicos motorizados por los sectores dirigentes liberales, subsistieron sensibilidades conservadoras y sentimientos reactivos a los cambios de conducta, sobre todo tratándose de las mujeres que padecían inferioridad jurídica debido al ordenamiento civil de 1869 . $^{7}$

El modelo benéfico asistencial, dirigido a paliar problemas como la pobreza, la mendicidad, el abandono de niños/as y las enfermedades, entre otros, se caracterizó durante esa etapa por la privatización del espacio público y la hegemonía del sistema mixto de

7 BARRANCOS, Dora. Sentidos, sentimientos y sensibilidades (1880-1930). Revista Latinoamericana de Estudios sobre Cuerpos, Emociones y Sociedad, núm. 15, noviembre de 2014, pp. 27-39, pp. $28,37$. 
protección ${ }^{8}$. Pese a su posición ciudadana desventajosa desde el punto de vista formal, muchas mujeres tuvieron un rol destacado como agentes no estatales en la provisión de asistencia, al colaborar con un Estado liberal que no contaba con recursos burocráticos y presupuestarios suficientes para hacer frente a los crecientes requerimientos de la población. Como indica Yolanda de Paz Trueba, dicho Estado reconoció la relevancia que adquiría para su sustentabilidad política la atención de las demandas originadas en los desajustes del proceso de modernización. Sin embargo, en razón de que su intervención conllevaría una intromisión en deberes morales que le correspondían a la sociedad, dejó gran parte de las mismas en manos de diversas entidades y contribuyó mediante el otorgamiento de subsidios. ${ }^{9}$

Si bien el ejercicio de la caridad no era privativo de las mujeres de la elite, sí es cierto que las integrantes de ese sector ocupaban las franjas dirigentes de muchas sociedades benéficas de la Capital Federal. Formaban parte de una elite nacional conformada, como describe Leandro Losada, por tres grandes grupos de familias: uno de orígenes coloniales y bonaerenses; otro de extranjeros llegados después de la Revolución de Mayo de 1810; y un tercero de familias de las provincias del Interior afincadas en la ciudad en la segunda mitad del siglo XIX e integrantes de la elite política que controló el gobierno nacional a partir de 1880 (momento en que culminó la integración política y territorial de la Argentina). Entre 1880 y 1910 estas familias dejaron atrás un pasado conflictivo y se integraron en un grupo de gran cohesión interna, que se erigió en el de mayor status y prestigio. Este proceso fue posibilitado por un universo social cerrado, cuya mejor expresión fue un mercado matrimonial endogámico, y por un cambio cultural profundo originado por condiciones materiales excepcionales y por un afán de sofisticación que se tradujo en un estilo de vida de tonos aristocráticos (en sintonía

8 MOREYRA, Beatriz. Cuestión social y políticas sociales en la Argentina: La modernidad periférica. Córdoba, 1900-1930. Bernal: Universidad Nacional de Quilmes, 2009, p. 22.

9 DE PAZ TRUEBA, Yolanda. Acción social y nuevo Estado liberal en Argentina: La participación de las mujeres en las instituciones del modelo mixto de atención de necesidades en el centro y sur bonaerenses. Secuencia, núm. 80, 2011, pp. 85-107, p. 88. 
con el eurocentrismo de la época), ritmado por los códigos de etiqueta y definido por el consumo suntuario y el refinamiento de usos y costumbres. Ese momento de máximo esplendor comenzó a eclipsarse desde mediados de la década de 1910, lo cual se profundizó en las dos siguientes por diversos factores, como la crisis del "régimen oligárquico", la reforma electoral de 1912 que estableció el sufragio secreto, obligatorio y universal, el triunfo de la Unión Cívica Radical en 1916, la ralentización de la economía y el errático desempeño del sector rural a partir de la década de 1920, la formación de sectores medios y el aumento del acceso a la educación y a consumos culturales y materiales de amplias franjas de la población. ${ }^{10}$

Algunas asociaciones benéficas de la época conducidas e integradas por mujeres de la elite eran de filiación católica explícita, pero incluso en otras que no lo eran militaban fieles de esta confesión, como sucedía en la Sociedad de Beneficencia de la Capital Federal, que era una agencia pública. A medida que avanzó el siglo XX, las mujeres católicas cobraron cada vez mayor protagonismo en las celebraciones religiosas, las comisiones parroquiales, las colectas, las peregrinaciones, la enseñanza del catecismo, la prensa, los centros de estudio y las entidades caritativas. Las "damas" tuvieron un trato fluido - aunque no exento de conflictos - con médicos, funcionarios, sacerdotes y miembros de la jerarquía eclesiástica, emitieron discursos permeados por la moral cristiana y, en ocasiones, confiaron a congregaciones de religiosas la administración de las instituciones que fundaron.

En este contexto, las mujeres allegadas a las actividades salesianas no constituyeron una excepción. Al igual que en otros países, se inscribieron individualmente en la Pía Unión de Cooperadores Salesianos, que había sido aprobada por las autoridades de la Iglesia como una tercera orden de la familia salesiana. Los/as integrantes de esa asociación eran nombrados/as por el Rector Mayor y debían acatar las disposiciones contenidas en un Reglamento

10 LOSADA, Leandro. La alta sociedad en la Buenos Aires de la Belle Epoque. Buenos Aires: Siglo XXI, 2008. 
redactado por Don Bosco en $1876^{11}$. De acuerdo con ese texto, podía enrolarse en ella cualquier persona que hubiera cumplido los dieciséis años y gozara de buena reputación civil y religiosa. El Director de cada Casa estaba autorizado para apuntar a los/as socios/as, cuyos nombres, apellidos y domicilios debía transmitir al Superior a fin de que fueran incorporados en el registro general.

Como señala Nicolás Moretti, el fundador de la congregación no pretendía hacer de los cooperadores simplemente el sostén de las obras de los salesianos, sino cristianos ejemplares y activos que ayudaran a propagar el espíritu católico. ${ }^{12}$ Los cooperadores y cooperadoras participaban en conferencias y recibían el Boletín Salesiano. Se les sugería modestia en el vestir, frugalidad en las comidas, sencillez en las habitaciones y moderación en las palabras. Además, debían hacer todos los años unas jornadas de retiro espiritual, llevar a cabo el ejercicio de la buena muerte y confesarse y comulgar en forma frecuente. Podían colaborar de manera práctica con la Obra salesiana mediante la difusión de los ejercicios espirituales, la promoción de las vocaciones religiosas, el fomento de la buena prensa, el ejercicio de la caridad con los niños y niñas propensos/as a extraviarse, la oración y la limosna. Asimismo, eran acreedores/as a significativos beneficios espirituales por sus labores piadosas y humanitarias.

De lo anterior se desprende que las condiciones de ingreso a la asociación eran idénticas para varones y mujeres, así como los requerimientos relativos al estilo de vida, las obligaciones, los modos de cooperación y las gracias espirituales. Lo mismo puede decirse sobre la lógica y común sujeción a las autoridades congregacionales y eclesiásticas en general. Sin embargo, otras disposiciones que se referían al accionar colectivo estaban construidas en función del dicotomismo sexual, trasuntando una división del trabajo que colocaba a las cooperadoras en una posición diferente a la de los cooperadores. Ese era el caso de las pautas que separaban a los grupos de acuerdo al sexo, contenidas en el Manual teórico-práctico de los

11 ARCHIVO HISTÓRICO SALESIANO PATAGÓNICO (AHSP), San Juan Bosco, La Pía Unión de los Cooperadores Salesianos, Dirección General de las Obras de Don Bosco, I diciembre de 1937.

12 MORETTI, Nicolás D., op. cit., p. 46. 
decuriones y directores de la Pía Asociación de los Cooperadores Salesianos redactado en 1893 por Don Miguel Rúa (sucesor de Don Bosco). De acuerdo a ellas, los nucleamientos de mujeres adquirían algunas particularidades, como el hecho de denominarse "subjuntas" y no "juntas" como los de varones. Del mismo modo que las juntas masculinas, las femeninas contaban con una Secretaria y una Tesorera pero, a diferencia de ellas, no tenían un Publicista sino, solamente si era necesario, una Escritora que debía someter sus iniciativas a la consideración de ese escritor. ${ }^{13}$

En suma, los roles de las mujeres fueron contemplados expresamente desde fines del siglo XIX en las regulaciones referidas a las personas que se inscribían individualmente como cooperadoras y también a aquellas que colaboraban de manera colectiva. Mediante la constitución de los grupos de mujeres, los salesianos favorecieron la acción social femenina basada en un propósito espiritual y vinculada con la situación de crisis que, a sus ojos, vivía la sociedad de su tiempo, en especial la infancia. Buscaron ampliar la base social que respaldaba su proyecto y preservar al mismo tiempo a las fieles al ofrecerles oportunidades de actuación pública de signo religioso.

En consonancia con el espíritu de esas resoluciones generales, las cooperadoras argentinas se reunieron para actuar de manera conjunta. En 1900 se conformó en Buenos Aires la Junta o Comisión Auxiliar de Señoras Cooperadoras, que contaba con una Comisión Auxiliar de Fiestas, cuyo objetivo era ayudar a quienes estaban realizando las tareas preparatorias del Segundo Congreso Internacional de Cooperadores Salesianos. ${ }^{14}$ Esta entidad actuaba en el ámbito de la Inspectoría San Francisco de Sales, cuya cabeza en la

13 ARCHIVO CENTRAL SALESIANO (ACS), Manual teórico-práctico para uso de los decuriones y directores de la Pía Asociación de los cooperadores salesianos, Turín, Tipografía Salesiana, 1897.

14 Las integrantes de la primera Comisión Central fueron: Presidenta Honoraria: Teodolina Fernández de Alvear, Presidenta efectiva: Enriqueta Alais de Vivot, Vice-Presidentas: Isabel de Anchorena y Justa Elortondo de García Férnández, Secretaria: Dolores Anchorena de Elortondo, Pro-Secretaria: Elena Tarragona de Sagasta, Tesorera: Ernestina Bullrich de Mosquera, Pro-Tesorera: Mercedes Terrero de Méndez, Socias o vocales: Mercedes B. de Casares, María Petit de Maglioni, Elisa A. de Bosch, Manuela Suárez de Figueroa, Cirila Suárez de Perdriel, Tomasa P. de Estrada, Josefa V. de Arrotea, Mercedes Elortondo de Alvear, Ana B. De Maglioni, Mercedes Uriarte de Terrero, María Cristina Sagasta de Eguía, Josefa S. de Pacheco, Magdalena V. de Martínez, Antonia B. de Fraboschi y Emilia Fraboschi. 
etapa abordada era el Padre José María Vespignani, quien se ocupó de fomentar la cooperación salesiana en todas sus formas. La continuidad en el tiempo de este agrupamiento, a diferencia del comité de señores cooperadores creado en el mismo año, justificaría la confección e impresión del Programa de la Comisión Auxiliar de Señoras Cooperadoras. Este documento podría haber sido redactado por el mencionado sacerdote entre 1904 y 1911, aproximadamente, de acuerdo con los indicios indirectos provistos por su contenido y por otras fuentes. ${ }^{15}$

El Programa se refería de manera central a la experiencia femenina, por lo cual adquiría una especificidad que permite apreciar con claridad los componentes genéricos de la normativa. Este documento, que constaba de veinte artículos, regulaba aspectos vinculados con la conformación y el plan de acción de la Comisión, enmarcándose en el Reglamento elaborado por Don Bosco. Al respecto, se indicaba que sus integrantes debían estar inscriptas a título individual como cooperadoras y se hacía especial hincapié en la importancia de que conocieran a fondo ese texto fundacional, que debía ser materia de estudio en las reuniones y que se encontraba impreso como anexo. Además, se estipulaba que la Comisión estaba bajo la órbita del "Superior Salesiano", o sea, el Inspector actuante en Buenos Aires. Se consideraba importante que las cooperadoras asociadas conocieran e internalizaran las normas escritas, por lo cual se explicitaba que la Presidenta debía procurar que las socias potenciales leyeran el documento y que el Director sería el encargado de repasar e interpretar su articulado en el transcurso de las reuniones.

En cuanto a la composición de la Comisión, en el Programa se indicaba que debía estar conformada por un mínimo de veinticinco integrantes y contar con autoridades como Presidenta, Vicepresidenta, Secretaria, Tesorera y Protesorera. Se le fijaba como objetivo general el de prestar cooperación a todas las áreas de la Obra salesiana en la Argentina, como los oratorios festivos, asilos y colegios, mediante la

15 En el texto hay una cita referida al año 1904, y en una carta de 1911 se hace referencia a una cláusula de un "reglamento" preparado por Vespignani que, debido a que se encuentra en el Programa, hace presumir que se podría estar haciendo referencia a ese documento. ACS, Programa de la Comisión Auxiliar de Señoras Cooperadoras, p. 22 y ACS, Carta dirigida por Enriqueta Alais de Vivot a José M. Vespignani, Buenos Aires, 29 de mayo de 1911. 
solicitud de subvenciones, becas y limosnas. También se les sugería efectuar donaciones personales de ropa y dinero. El Director guiaba la acción social femenina en las áreas detalladas, pues entre sus funciones se encontraban las de presidir las reuniones o delegar ese rol en otro sacerdote, preparar el orden del día junto con la Presidenta, aprobar las elecciones de autoridades, identificar las áreas prioritarias de cooperación y decidir sobre el destino de lo recolectado.

La reglamentación conllevaba mecanismos de control y tutela de estos sujetos femeninos considerados formalmente en condición de minoridad. Pese a ello, también les ofrecía una serie de oportunidades de socialización al interior de la comisión, así como de intervención y participación en la esfera pública, que prefiguraban nuevas modalidades de ejercicio de la ciudadanía. ${ }^{16}$ Esta normativa implicaba que las cooperadoras trascendieran los roles domésticos y desarrollaran habilidades en torno a aspectos legales, contables y políticos entre los que podemos listar los siguientes: recaudar dinero, llevar libros de caja, cobrar suscripciones, otorgar recibos, estudiar presupuestos, dar cuenta del estado del tesoro en las reuniones, contar con representantes con mandatos periódicos, ejercitar el voto secreto, tomar decisiones por mayoría, dar publicidad a sus actos, confeccionar órdenes del día, deliberar, tomar decisiones en conjunto, participar en asambleas, respetar el quorum, computar votos, confeccionar actas, memorias y balances, recorrer la ciudad buscando colaboraciones, visitar asilos y oratorios y representar a la Comisión ante las autoridades eclesiásticas y civiles. Esta modalidad de funcionamiento replicaba la de numerosas asociaciones de la época

16 El Código Civil, en vigencia desde 1871, sancionó la inferioridad jurídica de las mujeres: las casadas no podían administrar ni siquiera sus bienes propios y debían tener autorización de su marido para educarse, profesionalizarse, ejercer cualquier actividad económica y testimoniar ante la ley. Luego de la reforma de 1926 las casadas ya no necesitaron autorización para estudiar, profesionalizarse, comerciar, testimoniar o pleitear y el marido ya no administraba los bienes adquiridos por la esposa antes del matrimonio (aunque seguía al frente de la administración conyugal). Sin embargo, comprar, vender o cualquier forma de contrato requería autorización del marido; la patria potestad siguió siendo una facultad de los padres varones y el domicilio conyugal era fijado por el marido. Entendemos la ciudadanía de manera amplia, como una forma de pertenecer a una comunidad e involucrarse activamente en la resolución de sus problemas. La vía electoral no fue la única manera de intervenir en los asuntos de interés público y los grupos excluidos de la ciudadanía política encontraron otras estrategias de actuación en el contexto de la conformación del Estado nacional. Véase: DE PAZ TRUEBA, Yolanda. Mujeres y esfera pública. La campaña bonaerense entre 1880 y 1910. Rosario: Prohistoria Ediciones, 2010. 
integradas por varones, en un contexto en el cual se evaluaba de manera positiva la sociabilidad formal de carácter moderno, entendida como forma de intervención de la sociedad civil en la esfera de lo público basada en valores civilizatorios y republicanos.

Deben realizarse algunas precisiones para poder comprender con mayor profundidad las experiencias que estas normativas posibilitaron a unas cooperadoras a las cuales definían no solamente por su sexo, por profesar el catolicismo y por su militancia asociada a la congregación sino también por el hecho de que, del mismo modo que otras benefactoras asociadas de la época, eran integrantes de la elite. Las normativas recogían un repertorio de expresiones de la sociabilidad que eran propias de mujeres de ese sector encumbrado desde el punto de vista político, económico y social que buscaba construir un estilo de vida distinguido, civilizado, definido por la moderación y el autocontrol. Además, la colaboración con una causa considerada noble y justa como era la atención de los sectores más desposeídos, sobre todo de niños/as y jóvenes pobres, legitimaba a esa misma elite ante la sociedad. La adscripción a esta entidad no resumía el universo relacional de estas mujeres, varias de las cuales estaban unidas por lazos de parentesco y amistad y compartían esferas de sociabilidad menos formales.

El Programa muestra, además, que pese a la existencia de una normativa general de la Pía Unión que incluía artículos referidos al accionar individual y colectivo de las cooperadoras, la especificación de la constitución y los fines de los grupos femeninos conformados en la Argentina era sentida como una necesidad. Esto es confirmado también por la existencia de al menos otros siete documentos referidos a normas de organización de dicha Comisión. Se trata de borradores incompletos, sin fecha, manuscritos o mecanografiados que, a diferencia del Programa y del Reglamento que analizaremos en el próximo apartado, aparentemente no fueron terminados ni impresos. Si bien esto testimonia una evidente preocupación regulatoria de los sacerdotes que actuaban en el país, probablemente no fuera algo infrecuente entre los salesianos desperdigados por el mundo. El hallazgo en la caja de archivo en la que se encontraba el Programa de un documento casi idéntico al 
mismo, referido a la Asociación de Señoras Protectoras de las Obras Salesianas de Sevilla, es esclarecedor en este sentido. ${ }^{17}$

Sin embargo, es preciso reconocer que esos esfuerzos por sistematizar la acción social femenina no eran privativos de los salesianos, sino que se replicaban en otras asociaciones benéficas católicas de la época, pues tenían su raíz en las concepciones de la Iglesia en torno a la femineidad. En general, los sectores católicos consideraban que ciertas cualidades naturales, como la compasión y el espíritu de sacrificio, hacían a las mujeres especialmente aptas para las tareas caritativas. Legitimaban y valoraban sus contribuciones en el campo asistencial pero creían que sus iniciativas no podían dejarse libradas a su propio arbitrio. Afirmaban que el carácter pasional de las féminas, debido a que se guiaban más por los sentimientos $\mathrm{y}$ emociones que por la razón, imponía la necesidad de una conducción permanente. La importancia de contar con reglamentos específicos para los grupos de mujeres constituía una derivación de dichos valores y pautas generales que, del mismo modo que los textos regulatorios, sustentaban los intercambios en esas esferas de sociabilidad femenina.

Si bien la confección del Programa corrió a cargo del Inspector, Alais, quien fuera la Presidenta efectiva de la Comisión entre 1900 y 1919, tuvo cierta influencia en la organización normativa de la misma, tal como puede observarse en la correspondencia. ${ }^{18}$ En

17 Si bien podemos conjeturar que podría haber servido de inspiración al redactor del Programa, no podemos aseverarlo debido a que tampoco se consignan su fecha de emisión ni su autor. Sobre una base común, en el caso del Programa se agregaban algunos detalles referidos al funcionamiento que lo convertían en un documento más extenso que su supuesto modelo. Entre la principales adiciones, estaban las siguientes: el Superior y la Presidenta prepararían un apunte de los asuntos a tratarse en las reuniones; las cooperadoras podían confirmar en sus cargos a la Presidenta y la Vicepresidenta una vez concluidos sus mandatos, con aprobación del Superior; la Comisión contaba con Prosecretarias y Tesoreras $1^{\circ}$ y $2^{\circ}$; la Tesorera podía contar con un cobrador (en el documento sevillano la propia Tesorera debía efectuar la colecta); debía leerse el Reglamento de Don Bosco en las reuniones; se especificaba la forma de admisión de nuevas socias y se establecía el uso de una insignia. ACS, Asociación de Señoras Protectoras de las Obras Salesianas de Sevilla, Programa.

18 En el momento de asumir esa función, Alais, que había nacido en la Argentina en 1852, tenía cuarenta y ocho años y era viuda. Había estado casada durante veintitrés años con Narciso Vivot, un terrateniente pampeano con el cual había tenido nueve hijos. Su compromiso con la congregación no se reducía al ejercicio del puesto mencionado, ya que también se desempeñaba como Presidenta Honoraria de la Asociación de Ex Alumnas de María Auxiliadora. Para profundizar los aspectos que se expondrán aquí en relación a su correspondencia véase: 
razón de sus funciones directivas, se encontraba habilitada para tratar directamente con Vespignani, ya fuera en forma personal o epistolar. La mayor parte de sus misivas estaba destinada a mantenerlo informado y a consultar su parecer sobre diversos temas. Sus escritos dejan entrever que, aunque en líneas generales acataba las reglamentaciones y las indicaciones de su superior, en ocasiones contaba con libertad de acción y, sin dudas, de opinión. Muestran, además, que si bien Vespignani se preocupaba por guiarla y encauzar su accionar dentro de los marcos normativos y jerárquicos de la congregación, era receptivo a sus iniciativas, inquietudes y sugerencias.

Alais contribuyó a la aplicación práctica tanto del Programa como de la reglamentación general de la Pía Unión en la vida cotidiana de la Comisión. Bajo su dirección y con la supervisión del Inspector, se cumplían ciertas formalidades como la convocatoria a reuniones, la toma de decisiones colectivas, la redacción de órdenes del día, la elaboración de actas y la confección de balances. Asimismo, sus integrantes asistían a las misas y las conferencias reglamentarias. Alais también recurrió argumentativamente a la normativa para dirimir cuestiones extraordinarias. Por ejemplo, en 1911 le manifestó al Inspector su deseo de renunciar al cargo que detentaba. En ese momento, Vespignani le propuso permanecer en el puesto y le ofreció designar una "Vice". Ella le respondió que la manera correcta de hacerlo sería reunir a sus compañeras para tratar el asunto y para que ellas procedieran a elegirla: "Su Rcia no piensa que no se puede hacer así sin que las compañeras reunidas lo acepten y la nombren. Yo insisto en que deben aceptar mi renuncia y hacer una votación seria y nombrar los principales cargos de nuevo..."

En el caso anterior, puede interpretarse que el apego a la normativa operaba como una estrategia para garantizar la participación de las cooperadoras en la toma de decisiones. En la misma línea pueden situarse las quejas que emitía la Presidenta

BRACAMONTE, Lucía. La cooperación salesiana a través de la correspondencia entre Enriqueta Alais de Vivot y José M. Vespignani. Argentina, 1900-1919. En: GONÇALVES ALVES y otros (coords.), op. cit.

19 ACS, Carta dirigida por Enriqueta Alais de Vivot a José M. Vespignani, Buenos Aires, 29 de mayo de 1911. 
cuando la inasistencia de los sacerdotes a las reuniones les impedía sesionar, ya que de acuerdo con lo indicado en el Programa, no podían hacerlo sin la presencia del Inspector o de un clérigo delegado por éste. $^{20}$

Otro aspecto a destacar es que Alais se atrevió a emitir opiniones puntuales acerca del contenido de la reglamentación redactada por Vespignani para regular el accionar de la Comisión Central. Sus observaciones se referían a los principales cargos de autoridad dentro de la misma. Al respecto, manifestaba la necesidad de contar con dos Vicepresidentas y no con una como estipulaba el Programa que las regía: "[...] yo creo y hace mucho pienso que se debía nombrar una Vice $2^{\mathrm{a}}$ pero su Rcia cuando preparo el reglamento dejo solo una Vice [...]"21 Al parecer, las frecuentes y a veces extensas ausencias de la Capital Federal de quienes ocupaban estas posiciones dificultaban el normal funcionamiento del agrupamiento. Poder sesionar y tomar decisiones con cierta frecuencia era, a los ojos de esta cooperadora, algo crucial para poder garantizar el cumplimiento de sus objetivos y compromisos. Es evidente que la experiencia acumulada por ella en el ejercicio de sus funciones la conducía a reflexionar sobre cuestiones ubicadas en la intersección entre las prácticas - personales y colectivas - y el diseño normativo.

\section{Cambios en el campo de acción y la normativa de la Comisión Central en la década de 1920}

Durante el decenio de 1920, los sacerdotes efectuaron un recorte normativo y práctico de las funciones de la Comisión Central - que contribuía a sostener los proyectos de los salesianos y de las

20 Loc cit.

21 ACS, Carta dirigida por Enriqueta Alais de Vivot a José M. Vespignani, Buenos Aires, 29 de mayo de 1911; ACS, Carta dirigida por Enriqueta Alais de Vivot a José M. Vespignani, El Retiro, 29 de marzo de 1917; ACS, Carta dirigida por Enriqueta Alais de Vivot a José M. Vespignani, Buenos Aires, 25 de junio de 1917. 
Hijas de María Auxiliadora en todo el país - debido a la existencia de otras inspectorías y de nuevas comisiones. En cuanto al primer aspecto, en 1911 se había creado la Inspectoría San Francisco Javier, lo cual, sin embargo, no redundó inmediatamente en una reorganización de la cooperación salesiana. ${ }^{22}$ Más adelante, en 1926, la Inspectoría San Francisco Solano o Norte, con sede en Córdoba, se desmembró de la Inspectoría San Francisco de Sales, como consecuencia de lo cual se circunscribió finalmente el radio geográfico sobre el cual actuaba la Comisión Central.

En cuanto a las cooperadoras, en un contexto de incremento de la participación de mujeres en el movimiento católico y de necesidad creciente de obtener recursos para sostener los distintos emprendimientos salesianos, durante toda la década de 1920 se fueron configurando grupos femeninos que se sumaron a la primera comisión capitalina, que contaba con 123 integrantes. ${ }^{23}$ En efecto, se formalizaron agrupaciones de ese tenor en lugares como la Capital Federal, Bahía Blanca, Viedma, Eduardo Castex, Córdoba, Tucumán y Comodoro Rivadavia, que se regían por la normativa general de la Pía Unión. El Programa estipulaba que si bien su destinataria era la comisión radicada en Buenos Aires, sus prescripciones podían hacerse extensivas a las asociaciones del mismo carácter que se constituyeran en otras Casas bajo la autoridad de sus respectivos Directores. Sin embargo, pese a que en su articulado se preveía un alcance mayor, desconocemos si tuvo eco práctico en otros grupos además de los capitalinos.

Del Octavo Congreso Internacional de Cooperadores Salesianos, que se celebró en Turín en 1920, emanaron mayores precisiones acerca del accionar colectivo de las cooperadoras a nivel internacional que tuvieron eco en la comunidad salesiana argentina. ${ }^{24}$

22 En 1911 se crearon dos Inspectorías o Provincias Salesianas, la de San Francisco de Sales, con jurisdicción en la parte norte y territorio de La Pampa y la de San Francisco Javier, con jurisdicción en la parte sur de la provincia de Buenos Aires y los territorios nacionales de Río Negro, Neuquén, Chubut, Santa Cruz y Tierra del Fuego.

23 En 1900, la Comisión tenía 45 integrantes. Incluimos a quienes conformaban la Comisión Auxiliar de Fiestas. ACS, Actas del II Congreso Internacional de Cooperadores Salesianos, Buenos Aires, 1900, pp. 24-26 y ACS, Comisión Central de Sras. Cooperadoras Salesianas, Invitación, 15 de junio de 1920.

24 AHSP, San Juan Bosco, op. cit., p. 38-46. 
De acuerdo a lo manifestado por el Inspector Luis Pedemonte, en esa ocasión los Superiores decidieron que la Inspectoría San Francisco de Sales y la Inspectoría San Francisco Javier - que se encontraba bajo su supervisión -, tuvieran comisiones autónomas. En apariencia, esto dio lugar a la creación en ese mismo año de una subcomisión protectora de las misiones pampeanas y patagónicas que, pese a lo expresado y deseado por dicho sacerdote, en sus comienzos no fue independiente de la Comisión Central. ${ }^{25}$ Este nuevo grupo, presidido por Isabel Casares de $\mathrm{Nevares}^{26}$, también estaba radicado en la Capital Federal, debido a que la administración oficial de los Territorios Nacionales se realizaba desde esa ciudad y a que allí residía la mayor parte de los terratenientes y hacendados. Posteriormente, iniciando un proceso de paulatina autonomización, esa subcomisión se transformó en una comisión paralela a la Central.

Si bien los destinatarios de la asistencia de ambos grupos de cooperadoras se deslindaron desde un inicio, los mismos enfrentaron problemas de competencia debido a que actuaban en idéntico lugar geográfico y a que sus métodos de recaudación y redes de relaciones eran similares. Se generó un conflicto de tales proporciones entre las cooperadoras que el Inspector Valentín Bonetti y las Presidentas solicitaron la intervención de los Superiores de Turín para encontrar una solución. ${ }^{27}$ Finalmente, en 1926, la segunda comisión cambió su nombre por el de Junta Cooperadora de Señoras Misiones Salesianas de la Patagonia, se independizó definitivamente de la Comisión Central y pasó a estar bajo la órbita directa del Inspector actuante en la Inspectoría San Francisco Javier.

El Reglamento General de la Comisión Central de Señoras Cooperadoras Salesianas de Buenos Aires confeccionado por Vespignani, que en ese entonces se desempeñaba como Visitador Extraordinario, reflejaba los cambios en el escenario de actuación de la Comisión Central producto de la aparición de esas comisiones y de

25 AHSP, Carta dirigida por Luis Pedemonte a Ernestina Bullrich de Mosquera, Patagones, 25 de septiembre de 1921. Luis Pedemonte fue Inspector de la Inspectoría San Francisco Javier entre 1911 y 1924 . Lo sucedió el sacerdote Gaudencio Manachino.

26 Isabel Casares nació en París el 28 de octubre de 1884. Contrajo matrimonio con Jaime Francisco de Nevares, que se desempeñaba como abogado. Enviudó en 1920.

27 Valentín Bonetti se hizo cargo de la Inspectoría San Francisco de Sales entre 1922 y 1928. 
la creación de las nuevas inspectorías ${ }^{28}$. Pese a que, de hecho, su antigüedad, nombre y lugar de radicación otorgaban a ese núcleo una posición de preeminencia, este documento lo colocaba solamente como cabeza de las comisiones subsidiarias, auxiliares y locales creadas en el radio de acción de la Inspectoría San Francisco de Sales.

El Reglamento mantenía los objetivos, medios de acción, número mínimo de integrantes, principales autoridades y dirección sacerdotal presentes en el Programa. También eran similares las representaciones de género subyacentes. La siguiente cita de una obra de Monseñor Charles Gibier, incluida por Vespignani en el mismo, ilustra definiciones sexuales en torno a la femineidad análogas las que identificamos anteriormente:

A la mujer toca el ministerio del dolor; el ejercicio de la caridad es su campo de batalla. No espera más que una señal para marchar, una ocasión para sacrificarse. Señalándoles una tarea precisa, guiándolas discretamente se obtienen magníficos frutos de abnegación. Las señoras seriamente cristianas no faltan. La élite femenina existe más o menos por doquiera. Basta trazarles un reglamento y enrolarlas en una organización. La mujer le da al pobre algo de lo suyo y más aún le da algo de su corazón que vale mucho más. Pero [...] no lo olvidemos para que una asociación de caridad compuesta por señoras, funcione normalmente y eficazmente debe trazársele un reglamento suave, si se quiere bastante elástico, pero claro y preciso y suficientemente estricto como para reprimir ardores imprudentes e iniciativas que puedan comprometer. La caridad femenina puede llegar a hacer

28 El hecho de que en el Reglamento se mencionaran "otras inspectorías", sumado a la referencia a la obra de Ramos Mejía cuyos planos se aprobaron en 1927 y a una mención en una memoria, entre otros indicios, inducen a fecharlo en 1926. ACS, José M. Vespignani, Reglamento General de la Comisión Central de Señoras Cooperadoras Salesianas de Buenos Aires; ACS, Memoria del interinato, 7 de mayo de 1927. 
prodigios a condición de que se deje conducir y acepte una organización. ${ }^{29}$

En relación con esta visión de la condición femenina, seguía destacándose como algo fundamental que las cooperadoras conocieran e interiorizaran las normas escritas como guías de conducta y como marco para la toma de decisiones colectivas. El sacerdote era el productor y el único intérprete autorizado de los reglamentos que las cooperadoras debían acatar y cuya observancia tenían "derecho" a reclamar. Por su parte, la Presidenta debía hacerle conocer a cada nueva socia el Reglamento de Don Bosco y estaba obligada a hacer cumplir el documento dictado por Vespignani.

La estructura armada por el mencionado sacerdote para contextualizar la actividad de la Comisión, muestra que los salesianos continuaban fomentando la beneficencia como forma de sociabilidad e intervención de las mujeres de la elite en la arena pública. La misma seguía estando legitimada en cualidades enraizadas en la diferencia sexual - en especial la sensibilidad hacia los que sufrían y la capacidad de cuidado - que eran proyectadas en la misión asistencial entendida como un ejercicio social de la maternidad. En algunos puntos del Reglamento esto se reforzaba en comparación con el Programa, ya que se ponía énfasis en la importancia de la presencia efectiva de las integrantes de la Comisión en todos los emprendimientos, robusteciendo su carácter de esfera de sociabilidad presencial. Incluso, se indicaba que aquellas que se apartaran de las normas o del espíritu del documento, o dejaran de asistir sin aviso por tiempo notable a las reuniones, quedarían excluidas de hecho de la Comisión, mientras que en el Programa se aclaraba que la asistencia a todas las sesiones no era obligatoria. En suma, se les ofrecía la oportunidad de reunirse por un interés común, multiplicar las relaciones sociales fuera del ámbito doméstico y establecer nuevos vínculos relacionales con distintos actores del mundo político, religioso y económico. 
Pese a las similitudes apuntadas, el Reglamento era un documento mucho más extenso que el Programa, pues constaba de tres partes referidas al origen y fin de la asociación, organización de la Comisión y relación de la misma con los institutos de la Obra, e incluía también unos Estatutos de nueve puntos subdivididos a su vez en varios artículos. Además de la creencia en la necesidad de guiar la acción femenina, la minuciosidad con la cual se normaba cada uno de los aspectos podría responder al afianzamiento de la Comisión Central y al crecimiento numérico de sus integrantes. Creada en 1900 como "Auxiliar", se había ganado el derecho a eliminar de su nombre ese adjetivo al permanecer en el tiempo, triplicar sus miembros y dar muestras de su poder de convocatoria y eficacia. Después de dos décadas y media, sus labores se habían diversificado y se habían acrecentado los recursos monetarios y no monetarios que recaudaba, acompañando la extraordinaria expansión del proyecto salesiano que coadyuvaba a sostener. Todo esto podría explicar los cambios en el diseño normativo relacionados con cuestiones organizativas.

Entre las ampliaciones y especificaciones introducidas se encontraba el agregado de subcomisiones. Como señalamos anteriormente, la primera Comisión Central fue acompañada por una Comisión Auxiliar de Fiestas. El Reglamento sumaba una Comisión Honoraria, de carácter consultivo, constituida por Señoras Cooperadoras que, por su posición y estado, gozaban de prestigio social y habían adquirido especiales "benemerencias" con la Obra de Don Bosco pero que no participaban directamente en la acción social de las cooperadoras. De esta manera, se mantenía ligadas a la Comisión a aquellas "damas" que eran grandes benefactoras. Por su parte, la nueva Comisión Revisora de Cuentas tenía a su cargo el estudio de los presupuestos y la fiscalización de los balances y registros tanto de la Comisión Central como de las Auxiliares, evidenciando la envergadura que habían adquirido las cuestiones financieras. En conexión con esto, se enumeraron de la siguiente manera los procedimientos aconsejados para obtener fondos: organización de exposiciones, certámenes, concursos, obras teatrales, festivales, desfiles, rifas, bazares, colectas y becas; venta de productos de los talleres o las librerías salesianas y recepción de herencias, legados o donaciones. 
Otra de las innovaciones introducidas fue la descripción minuciosa de diferentes categorías de socias, que respondía a las diferentes formas de contribución de quienes, cada vez en mayor número, adherían al trabajo de este grupo institucionalizado de cooperadoras. Se dividían en activas, que formaban parte de la Comisión como vocales, abonaban una cuota mensual no inferior a $\$$ $1 \mathrm{~m} / \mathrm{n}$, tenían voz y voto y eran elegibles para los cargos directivos; adherentes o contribuyentes, que no pudiendo aportar su trabajo en forma directa contribuían con una suma periódica, voluntaria, al sostenimiento de las obras; y honorarias, que habiendo contribuido con su labor "abnegada" y con "ofertas notables" a la obra, por razones especiales se veían privadas de prestar su concurso personal y habían merecido esta distinción de parte de los Rvmos. Superiores Mayores. ${ }^{30}$

En cuanto a la constitución y autoridades de la Comisión, en el articulado del Reglamento se introdujo la explicación exhaustiva del mecanismo asambleario y electoral y se creó un Comité Ejecutivo o Consejo Directivo compuesto por el Inspector, la Presidenta, las tres Vicepresidentas, la Secretaria y la Tesorera. Cabe destacar que parte de este diseño de los cargos de autoridad coincidía con las sugerencias que Alais había realizado años antes, acerca de la conveniencia de contar con dos Vicepresidentas.

En relación con la anterior, puede afirmarse que el documento recogió también, al menos parcialmente, la experiencia que las cooperadoras, representadas por sus dirigentes, habían acumulado en el ejercicio de sus funciones. De hecho, así como había sucedido con Alais, las Presidentas de la década de 1920 - Ernestina Bullrich de Mosquera (1920-1922) y María Delia Malbrán de Vedoya

30 Se agregaban, además, las siguientes figuras: "Se consideran Beneméritas y Protectoras aquellas personas que por su autoridad, servicios profesionales o considerables auxilios morales o materiales han favorecido o favorecen a la Obra de Don Bosco y se han hecho acreedores al Diploma de Benemerencia. Celadoras colectoras son aquellas personas que con debida autorización del Revmo. Sr. Inspector y provistas del talonario de recibos, recogen limosnas, libres o periódicas de las cooperadoras o de otras personas caritativas. Suscritoras son aquellas personas o cooperadoras, o no, que se han comprometido a dar periódicamente una suma determinada en favor de las obras y cuyos nombres están inscritos en el Álbum de Oro de la Comisión; y reciben el Boletín Salesiano y son invitados especiales a los actos públicos de la Obra.” Ibid., pp. 30 y 31. 
$(1922-1926)^{31}$ - tuvieron incidencia sobre la organización normativa que analizamos. Esta influencia se desplegó por dos vías paralelas: la de las prácticas, signada por tensiones provocadas por la creación de la Subcomisión del Sud y su proceso de autonomización; y la discursiva, plasmada en las cartas y los proyectos de reglamentación dirigidos a los Inspectores y a Vespignani.

Puede afirmarse que el Reglamento constituyó una respuesta a las demandas de las cooperadoras y una forma de solucionar los conflictos que las aquejaban. Las disposiciones de su articulado que, como las siguientes, conminaban a las integrantes de la Comisión a establecer relaciones armoniosas entre sí y con los núcleos análogos de otras Inspectorías, evocaban los problemas suscitados al producirse la escisión de la Subcomisión dedicada a proteger a las misiones de la Patagonia:

19. Con el favor de Dios y bajo el manto de María Auxiliadora, las beneméritas Cooperadoras conservarán las relaciones más cordiales entre sí y colectivamente con las comisiones similares.

20. La Comisión Central que tiene superintendencia sobre las Comisiones Auxiliares o Locales, se esforzará en mantener amistosas relaciones con las juntas o comisiones dependientes de otras Inspectorías o Instituciones, evitando desinteligencias, promoviendo actos de acercamiento, e invitando o aceptando gustosas las invitaciones remitidas por esas entidades. ${ }^{32}$

Pese a que, como ya explicamos, finalmente los deseos de Pedemonte y las disposiciones de los Superiores se impusieron y condujeron a la separación de las dos comisiones, durante los años que duró el proceso las Presidentas Bullrich y Malbrán no se privaron

31 Ernestina Bullrich nació en Buenos Aires el 4 de junio de 1866. Se casó con Enrique G. Mosquera. Participó en la Liga Argentina de Damas Católicas y en las Conferencias Vicentinas. Falleció el 4 de septiembre de 1922. María Delia Malbrán nació en 1867 y contrajo matrimonio con Enrique Vedoya.

32 ACS, José M. Vespignani, op. cit., p. 28. 
de emitir opiniones acerca de la inconveniencia de dicha decisión, en contraposición con lo expresado por el mencionado sacerdote y por Casares de Nevares, la Presidenta de la Subcomisión. De acuerdo a sus argumentos, independientemente de cuál fuese la solución al problema a la que se arribara, el componente reglamentario era algo central a considerar. En 1923, Malbrán le expresó a Vespignani que el conflicto organizativo no se había solucionado por falta de un reglamento que indicara las normas a seguir. ${ }^{33}$ Ella y sus colaboradoras le realizaron el mismo reclamo a Bonetti, tanto en persona como por carta, como lo evidencian las siguientes palabras contenidas en una epístola de la Presidenta:

Conversando con la señora María Josefa [...] de Padilla hemos constatado una vez más la imperiosa necesidad de organizar un reglamento para la Comisión de Señoras Cooperadoras Salesianas, como lo insinuamos a V. R. en nuestra primera entrevista, después de haberse elegido la nueva Comisión. La creación de un reglamento con artículos precisos y terminantes sería beneficioso en todo sentido y constituiría para la Comisión una guía de valor inapreciable. ${ }^{34}$

Incluso, en ese mismo año Malbrán redactó un proyecto de reglamentación previendo dos escenarios posibles: la unión o la separación de las dos comisiones. En este manuscrito detallaba el estado de situación y presentaba los "Puntos sobre los cuales convendrá llegar a un acuerdo si las comisiones se separan" y los "Puntos sobre los cuales convendrá llegar a un acuerdo si las Comisiones Central y del Sud marchan unidas" ${ }^{35}$. Sus disquisiciones versaban sobre los principales tópicos en disputa: las denominaciones de las comisiones, las modalidades de realización de las colectas y los

33 ACS, Carta dirigida por María Delia Malbrán de Vedoya a José M. Vespignani, Buenos Aires, 6 de octubre de 1923.

34 ACS, Carta dirigida por María Delia Malbrán de Vedoya a Valentín Bonetti, Buenos Aires, 30 de mayo de 1923.

35 ACS, Escrito de María Delia Malbrán de Vedoya, septiembre de 1923. 
criterios para la distribución de los fondos. Estas cuestiones encerraban un problema de ejercicio del poder intra género ya que, en definitiva, lo que debía dirimirse era si el grupo que atendía las necesidades de la Obra en el sur del país era dependiente de la Comisión Central y, en consecuencia, debía rendirle cuentas, o si podía actuar de manera autónoma.

Estos manuscritos confeccionados por Malbrán dan cuenta de sus cuotas de poder e iniciativa, así como de la seguridad de que sus sugerencias serían tomadas en consideración por los sacerdotes, a los cuales ya había presentado opiniones y recomendaciones detalladas sobre otros asuntos, como los mecanismos electorales ${ }^{36}$. Su actitud marca, además, una línea de continuidad con etapas precedentes en cuanto al tipo de relaciones establecidas entre la máxima autoridad efectiva de la Comisión y sus superiores. Si bien no debe sobredimensionarse el poder de las cooperadoras, tampoco puede desconocerse que las autoridades de la Comisión Central se resistieron al desmembramiento de la misma, apelaron a los sacerdotes para que actuaran como árbitros, contribuyeron a la dilación durante seis años la solución al conflicto e influyeron, al menos parcialmente, sobre la organización normativa que dio marco a su propio accionar colectivo. El dictado del Reglamento, más allá de los cambios y conflictos puntuales que pudieron darle origen, tuvo el valor de haber constituido definitivamente a esta figura colectiva pionera en la organización de las cooperadoras argentinas.

\section{Consideraciones finales}

Los salesianos compartían el concepto de diferencia sexual extendido en la cosmovisión de la época, que atribuía a las mujeres características específicas enraizadas en la naturaleza y conllevaba una división de las esferas públicas y privadas en función del sexo. Si 
bien las disposiciones estudiadas no tuvieron en sí mismas la intención de subvertir las relaciones de género, pues promovieron las tareas benéficas de las mujeres enfatizando sus aristas sociales sin intenciones emancipatorias al estilo, por ejemplo, de los feminismos liberal y de izquierda, es innegable que avalaron mutaciones relevantes en la condición femenina. De acuerdo con las cláusulas de las normativas escritas analizadas, las comisiones eran dirigidas y controladas por los sacerdotes y mantenían el propósito tradicional de ocuparse de los necesitados - en especial de los niños y niñas propio de los antiguos grupos conservadores y piadosos. Sin embargo, las prácticas de sociabilidad diseñadas en las normativas implicaban una inserción en la esfera pública y un ejercicio ciudadano pese a las restricciones formales en las prerrogativas políticas y las capacidades civiles de las mujeres.

Otras agrupaciones benéficas de la época, católicas y no católicas, contaban con reglamentos que posibilitaban algunas prácticas similares, lo cual induce a explicar también la razón de ser y las características de estas regulaciones en otros dos aspectos además de los ya señalados. El primero es el hecho de que abrevaban en construcciones de género basadas en el concepto de diferencia sexual natural que estaban extendidas en la época más allá del universo católico y que asignaban a las mujeres determinados roles y esferas de actuación legítimos. En segundo término, esas similitudes nos hablan también de la necesidad de distinguir analíticamente, aunque no desagregar, ciertas formas de sociabilidad del contenido ideológico que se deseaba transmitir a través de ellas para comprenderlas en el marco más general de una sociabilidad propia de la elite. En parte, esas experiencias eran singulares por su carácter católico y salesiano, pero también mostraban la extensión de ciertas definiciones de la femineidad extendidas en la época y de formas de sociabilidad propias de los estratos altos de la sociedad de Buenos Aires.

Fue Vespignani quien, con aprobación de otros sacerdotes, diseñó el Programa y el Reglamento, fijando las modalidades de constitución y funcionamiento de la Comisión Central y poniendo en evidencia que el proyecto salesiano se desplegaba a nivel internacional con un mismo espíritu pero que eso no impedía una adaptación a las particularidades locales. Sin embargo, las cooperadoras, representadas por las Presidentas del agrupamiento que 
eran interlocutoras privilegiadas de los Inspectores, también tuvieron la posibilidad de expresar sus ideas y preocupaciones en relación al diseño normativo, adoptando un papel activo en la configuración de su propio campo de acción. Esta faceta aparece al dejar de lado el análisis del contenido de estos dos documentos para contrastarlos con otro tipo de fuentes. La letra de la norma, si bien contiene elementos contextuales, no da cuenta necesariamente del papel que juegan las relaciones de género. Por su parte, las epístolas analizadas permiten observar procesos de carácter interno que se desenvolvían al mismo tiempo que se desplegaba una unidad de acción en el espacio público y una labor propagandística que ensalzaba sin fisuras la imagen y la tarea de las integrantes de la Comisión.

Las cartas escritas por las Presidentas revelan que la necesidad de contar con un reglamento no constituía solamente una preocupación o una imposición de los sacerdotes salesianos en consonancia con el pensamiento católico acerca de la naturaleza femenina, sino que también fue sentida, expresada y promovida por las mismas cooperadoras. En síntesis, las propias involucradas tuvieron la posibilidad de influir en la generación, evolución y puesta en práctica de las normas, mostrando su capacidad para hacerse oír y la receptividad de los sacerdotes implicados - en especial de Vespignani - para adaptar las reglas trazadas a circunstancias cambiantes.

Las normas escritas analizadas reconocen su origen en dispositivos normalizadores de tipo religioso pero no aparecen como construcciones impuestas sino como productos de procesos de interacción en los cuales los roles y las relaciones de género - entre sacerdotes y Presidentas, y entre las propias cooperadoras - tuvieron un rol fundamental. En el tránsito por este espacio de sociabilidad relacionado con actividades asistenciales, a partir de la interacción con otros/as, las Presidentas establecieron nexos que definieron las estrategias futuras de las cooperadoras asociadas, debido a que les brindaron e instrumentos como los de tipo normativo que acataban pero que también ponían en cuestión. En su puesta en práctica, la reglamentación, además de ser una estructura condicionante y de control, era también una herramienta a la cual estas benefactoras podían apelar para defender sus derechos y de la cual podían hacer uso para desenvolverse en las diferentes situaciones. Sin embargo, el 
análisis realizado alerta sobre la necesidad de no reducir de manera simplista la mirada a los procesos de imposición-transgresión, adoptando un enfoque más complejo que permita atisbar también los consensos. En este sentido, se observa que existía un acuerdo básico entre las personas involucradas acerca de la forma en que se concebía el rol benéfico de las mujeres, así como sobre la importancia del componente reglamentario para ordenar la sociabilidad.

RECEBIDO EM: 01/03/2017 APROVADO EM: 01/06/2017 